\title{
Blooming gelatin: an individual additive for enhancing nanoapatite precipitation, physical properties, and osteoblastic responses of nanostructured macroporous calcium phosphate bone cements
}

This article was published in the following Dove Press journal:

International Journal of Nanomedicine

23 January 2017

Number of times this article has been viewed

\author{
Ziba Orshesh \\ Saeed Hesaraki \\ Ali Khanlarkhani \\ Biomaterials Group, Nanotechnology \\ and Advanced Materials Department, \\ Materials and Energy Research \\ Center, Alborz, Iran
}

\begin{abstract}
In recent years, there has been a great interest in using natural polymers in the composition of calcium phosphate bone cements to enhance their physical, mechanical, and biological performance. Gelatin is a partially hydrolyzed form of collagen, a natural component of bone matrix. In this study, the effect of blooming gelatin on the nanohydroxyapatite precipitation, physical and mechanical properties, and cellular responses of a calcium phosphate bone cement (CPC) was investigated. Various concentrations of blooming gelatin $(2,5$, and 8 wt.\%) were used as the cement liquid and an equimolar mixture of tetracalcium phosphate and dicalcium phosphate was used as solid phase. The CPC without any gelatin additive was also evaluated as a control group. The results showed that gelatin accelerated hydraulic reactions of the cement paste, in which the reactants were immediately converted into nanostructured apatite precipitates after hardening. Gelatin molecules induced 4\%-10\% macropores $(10-300 \mu \mathrm{m})$ into the cement structure, decreased initial setting time by $\sim 190 \%$, and improved mechanical strength of the as-set cement. Variation in the above-mentioned properties was influenced by the gelatin concentration and progressed with increasing the gelatin content. The numbers of the G-292 osteoblastic cells on gelatin-containing CPCs were higher than the control group at entire culture times (1-14 days), meanwhile better alkaline phosphatase (ALP) activity was determined using blooming gelatin additive. The observation of cell morphologies on the cement surfaces revealed an appropriate cell attachment with extended cell membranes on the cements. Overall, adding gelatin to the composition of CPC improved the handling characteristics such as setting time and mechanical properties, enhanced nanoapatite precipitation, and augmented the early cell proliferation rate and ALP activity.
\end{abstract}

Keywords: calcium phosphate cement, nanoapatite, cell studies, macroporosity, bone substitute, blooming gelatin

\section{Introduction}

In spite of many suitable materials available for bone substitution, calcium phosphate bone cements (CPC) are the most interesting candidates for this purpose, because they are moldable materials, which are converted to bone-like apatite phase after implantation. ${ }^{1}$ However, besides their intriguing properties, they have some shortcomings that necessitate attempting to modify them. The poor mechanical strength, especially after setting (at early stage of implantation), slow hydraulic reactions, leading
Correspondence: Saeed Hesaraki Biomaterials Group, Nanotechnology and Advanced Materials Department, Materials and Energy Research Center, PO Box: 31787/3 I6, Alborz, Iran Tel +98263620 4l 3 I

Email s-hesaraki@merc.ac.ir 
to relaxed apatite precipitation, and lack of macroporosity and hence slow in vivo resorption and tissue ingrowth can be mentioned as some drawbacks. ${ }^{2,3}$ Several additives, especially in the form of natural polymers, have been used to correct the physical and biological properties of CPCs. ${ }^{4-7}$

Gelatin is a partially hydrolyzed form of collagen, which is a natural component of bone matrix. Gelatin, in its various physical forms, has been widely used in bone-related composites to enhance the physical and biological properties. The promising effects of gelatin on osteointegration of threedimensional gelatin-coated hydroxyapatite (HA) foams have been described by Gil-Albarova et al. ${ }^{8}$ Gelatin microspheres as drug carriers were also incorporated into CPC to enhance bone formation in osteoporosis. ${ }^{9}$ Teotia et al synthesized injectable bone cement comprising a mixture of calcium sulfate, HA, and gelatin and proved that gelatin can enhance cell proliferation and ALP activity of human osteosarcoma cells, in this system. ${ }^{10}$ Habraken et $\mathrm{al}^{11}$ improved the handling properties and biodegradation of CPCs using gelatin microspheres. The foaming capacity and handling properties of a gelatin-incorporated $\alpha$-tricalcium phosphate-base CPC were recently evaluated by Montufar et al. ${ }^{12}$ The authors showed that gelatin additive improves the cohesion and injectability of the cement paste.

From the literature survey, it is clear that a few studies have been done on gelatin-containing CPCs and the existing papers have mainly focused on the physical and handling properties of these types of bone filling materials. In this study, tetracalcium phosphate (TTCP)-based cement, a wide-spread type of bone cement, was selected and the research was motivated on the effect of adding various concentrations of gelatin on the hydraulic reactions, mechanical and physical properties, and finally osteoblastic cell responses of this cement.

\section{Materials and methods}

\section{Cement formulation and preparation}

TTCP was synthesized by the high-temperature solid-state reaction of an equimolar mixture of calcium carbonate and dicalcium phosphate anhydrate (DCPA) powders (both of them were purchased from Merck, Germany). ${ }^{13}$ The mixture was heated at $1,500^{\circ} \mathrm{C}$ for $6 \mathrm{~h}$ and then quenched to room temperature. The product was manually ground in an agate mortar with a pestle and then was further ground in a planetary ball mill in ethanol for $1 \mathrm{~h}$.

The powder phase of the CPC was prepared by mixing the synthesized TTCP, $\mathrm{Ca}_{4}\left(\mathrm{PO}_{4}\right)_{2} \mathrm{O}$ (with mean particle size of $12.1 \pm 2.3 \mu \mathrm{m})$, and commercially available DCPA, $\mathrm{CaHPO}_{4}$ (with mean particle size of $6.5 \pm 1.2 \mu \mathrm{m}$ ) at a molecular ratio of $1: 1$. A 6 wt. $\%$ solution of $\mathrm{Na}_{2} \mathrm{HPO}_{4}$ with various concentrations of gelatin type B (225 bloom; Sigma-Aldrich) were prepared as liquid phase. To dissolve the gelatin powder into the phosphate solution, a heating process up to $80^{\circ} \mathrm{C}$ was performed. Table 1 shows the various CPC formulations along with the code of each one. To prepare the cement paste, the powder $(\mathrm{P})$ and liquid (L) phases were mixed in a mortar (at a constant $\mathrm{L} / \mathrm{P}$ ratio of $0.65 \mathrm{~mL} / \mathrm{g}$ ) at $37^{\circ} \mathrm{C}$ and stirred for $60 \pm 5 \mathrm{~s}$ until a homogeneous paste was achieved.

\section{Characterization}

\section{Initial and final setting times}

The powder and liquid phases were mixed in a mortar for $60 \mathrm{~s}$ and the initial and final setting times (Is and Fs, respectively) of the cement were measured by Gillmore needles, at $37^{\circ} \mathrm{C}$ according to the ASTM standard C266-89.

\section{Density and porosity}

Bulk density $\left(\mathrm{D}_{\mathrm{b}}\right)$ of the CPCs, the volume of the macropores $\left(\mathrm{P}_{\mathrm{ma}}\right)$, that is, the large pores produced by the presence of gelatin, the volume of the micropores $\left(\mathrm{P}_{\mathrm{mi}}\right)$, and total porosity $\left(\mathrm{P}_{\mathrm{t}}\right)$ of the cements were recorded using the following equations: ${ }^{14}$

$$
\begin{gathered}
D_{b}=\frac{M}{V} \\
P_{t}=\frac{1-D_{b}}{D_{p}} \times 100
\end{gathered}
$$

Table I Formulation of various CPCs with or without gelatin

\begin{tabular}{lllll}
\hline Sample code & Powder phase & $\begin{array}{l}\text { Concentration of } \\
\mathbf{N a}_{2} \mathrm{HPO}_{4} \text { in the } \\
\text { liquid phase (wt.\%) }\end{array}$ & $\begin{array}{l}\text { Concentration } \\
\text { of gelatin in the } \\
\text { liquid phase (\%) }\end{array}$ & $\begin{array}{l}\text { Liquid/powder } \\
\text { ratio (mL/g) }\end{array}$ \\
\hline CPC & TTCP + DCPA & 6 & 0 & 0.65 \\
CPC-G2 & TTCP + DCPA & 6 & 2 & 0.65 \\
CPC-G5 & TTCP + DCPA & 6 & 5 & 0.65 \\
CPC-G8 & TTCP + DCPA & 6 & 8 & 0.65 \\
\hline
\end{tabular}

Abbreviations: CPC, calcium phosphate bone cement; DCPA, dicalcium phosphate anhydrate; TTCP, tetracalcium phosphate. 


$$
\begin{gathered}
\mathrm{P}_{\mathrm{ma}}=\frac{1-\mathrm{D}_{\mathrm{b}}}{\mathrm{D}_{\text {control }}} \times 100 \\
\mathrm{P}_{\mathrm{mi}}=\mathrm{P}_{\mathrm{t}}-\mathrm{P}_{\mathrm{ma}}
\end{gathered}
$$

where $\mathrm{M}$ is the mass and $\mathrm{V}$ is the volume of samples, $\mathrm{D}_{\mathrm{p}}$ powder density of the samples obtained by picnometry, and $\mathrm{D}_{\text {control }}$ is the bulk density of control group (CPC without gelatin).

\section{Compressive strength}

For compressive strength (CS) measurements, the cement paste was placed in a split of a cylindrical Teflon mold with $12 \mathrm{~mm}$ height and $6 \mathrm{~mm}$ diameter to obtain cylindrical specimens. The $\mathrm{CS}$ was recorded after setting (at $37^{\circ} \mathrm{C}$ ) and soaking in a simulated body fluid (SBF) at $37^{\circ} \mathrm{C}$ for 7 days. It should be noted that the SBF solution was prepared in accordance with the Kokubo's specification. ${ }^{15}$ For the mechanical strength test, a universal testing machine (STM 20; Santam Ltd) with a crosshead speed of $1 \mathrm{~mm} / \mathrm{min}$ was used.

\section{Fourier transform infrared spectroscopy}

To estimate the interactions between gelatin and calcium phosphate, Fourier transforming infrared (FTIR) spectra of the cement powder, gelatin powder, and a combination of calcium phosphate powder and gelatin solutions (the as-set cements) were determined and compared to each other. Moreover, the FTIR spectra of the samples after soaking in the SBF solution for 7 days were also determined. The infrared spectra between 4,000 and $400 \mathrm{~cm}^{-1}$ were measured at a resolution of $2 \mathrm{~cm}^{-1}$ using FTIR Spectrum RXI, Perkin Elmer, USA.

\section{Phase composition and morphology}

To evaluate the phase composition of the cements, X-ray diffraction analysis (XRD) was performed. The data were acquired from 10 to 50 degrees with a scan rate of 0.02 20/s using a Philips PW 3710 X-ray diffractometer with $\mathrm{CuK}_{\alpha}$ radiation.

The microstructure of the cements was also observed with scanning electron microscopy (SEM, S360 Cambridge) at an operating voltage of $15 \mathrm{kV}$. The surfaces of the samples were coated with a thin layer of gold before the SEM analysis.

To determine the macropore sizes of the cements produced by the gelatin incorporation, the cross-sectional SEM images of the samples were taken and distribution of the pores (pore size in the range of 10-500 $\mu \mathrm{m}$ ) was directly measured from these images using SemAphore 4.0 software. ${ }^{16}$ It should be noted that more than 15 SEM images from different depths of cross-sections of each sample group were prepared and analyzed by the software.

\section{Gelatin release test}

To determine the fate of the gelatin after soaking the cements in the SBF solution, some experiments were performed. Thermogravimetry analysis (TG) was employed to recognize the presence of gelatin, and to estimate its concentration in both as-set cement and those soaked in SBF for 14 days. In this experiment, the change in weight of the samples against temperature was plotted when the samples were heated up to $600^{\circ} \mathrm{C}$ in a thermogravimetry device (PL-STA 1600 ; England) at a heating rate of $5^{\circ} \mathrm{C} / \mathrm{min}$.

The release of gelatin from the cements into the SBF solution was also monitored. In more detail, a disc-shaped sample (10 $\mathrm{mm}$ in diameter and $3 \mathrm{~mm}$ in height) was immersed in the SBF solution, in a sample to $\mathrm{SBF}$ ratio of $1 \mathrm{~g} / 100 \mathrm{~mL}$ and stored at $37^{\circ} \mathrm{C}$ up to 14 days. The concentration of gelatin in the SBF was determined at days 1, 7, and 14 by ultraviolet (UV) absorbance at $336 \mathrm{~nm}$ (Perkin Elmer Lambda 25; USA) according to the method described elsewhere. ${ }^{17}$ It should be noted that the whole of the SBF solution removed for the UV-visible test was discarded and replaced with a fresh solution for evaluating at the next period.

\section{Cell studies}

In this part of the study, the cell adhesion, proliferation, and ALP activity were determined using G-292 human osteosarcoma cells. G-292 cell lines were purchased from the cell bank of Pasteur Institute of Iran. The cells were cultured in Dulbecco's Modified Eagle's Medium (Gibco-BRL, Life Technologies, Grand Island, NY, USA) supplemented with $15 \%$ fetal bovine serum (Dainippon Pharmaceutical, Osaka, Japan) and $100 \mathrm{U} / \mathrm{mL}$ penicillin and $100 \mathrm{mg} / \mathrm{mL}$ streptomycin (Gibco-BRL, Life Technologies) in 5\% $\mathrm{CO}_{2}$ and 95\% air atmosphere at $37^{\circ} \mathrm{C}$ for 1 week. The medium was changed every 2 days. The confluent cells were dissociated with trypsin and subcultured to three passages that were used for the tests.

CPC discs (10 $\mathrm{mm}$ in diameter and $5 \mathrm{~mm}$ in height) were disinfected using $70 \%$ ethanol and the cells were seeded on the tops of them at a density of $1 \times 10^{4}$ cells $/$ sample $\left(12,700 \mathrm{cell} / \mathrm{cm}^{2}\right)$. The cell/specimen constructs were placed into 24-well culture plates and left undisturbed in an incubator for $3 \mathrm{~h}$ to allow cell attachment. Then, an additional $3 \mathrm{~mL}$ of culture medium was added into each well and kept in a humidified incubator at $37^{\circ} \mathrm{C}$ with $95 \%$ air and $5 \% \mathrm{CO}_{2}$ for $1,3,7$, and 14 days. The medium was changed every 2 days. 
The (3-\{4,5-dimethylthiazol-2yl\}-2,5-diphenyl-2Htetrazolium bromide) (MTT) assay was employed to determine proliferation of the cells on CPC discs. ${ }^{18}$ For this purpose, at the end of each period, the medium was replaced with MTT solution followed by incubation at $37^{\circ} \mathrm{C}$ for $4 \mathrm{~h}$ in a fully humidified atmosphere of $5 \% \mathrm{CO}_{2}$. The MTT was taken up by active cells and reduced in the mitochondria to insoluble purple formazan granules. Subsequently, the medium was discarded and the precipitated formazan was dissolved in dimethylsulfoxide, and the absorption of purple solution was read using a microplate spectrophotometer (BIO-TEK Elx 800; Highland park, IL, USA) at a wavelength of $570 \mathrm{~nm}$. To determine the number of cells attached onto the samples, a calibration curve was made by determining the absorbance of known cell concentrations.

The morphology of the cells attached onto the surfaces of the specimens was also evaluated. The cells were cultured on top of the cements as described above. After 7 days, the culture medium was detached, the specimens were rinsed with phosphate-buffered saline (PBS) twice, and the cells were fixed with $500 \mathrm{~mL} /$ well of $3 \%$ glutaraldehyde solution (diluted from $50 \%$ glutaraldehyde solution in PBS). After $30 \mathrm{~min}$, samples were rinsed again and kept in PBS at $4^{\circ} \mathrm{C}$. Then, the cells were fixed with $1 \%$ osmium tetroxide (Polyscience, Warmington, PA, USA) and dehydrated in ethanol solutions of varying concentration $(30 \%, 50 \%, 70 \%, 90 \%$, and $100 \%$ ), for $\sim 20 \mathrm{~min}$ at each concentration. Finally, the specimens were dried in air, coated with gold, and analyzed by the SEM device described in the section on phase composition and morphology.

The ALP activity, an early marker of osteodifferentiation, was evaluated by the enzymatic transformation of 4-nitrophenyl phosphate disodium salt into p-nitrophenol at pH 10.2 according to the method described elsewhere. ${ }^{19}$

\section{Statistical analysis}

The data were processed using software Excel 2010. The results are presented as mean \pm standard deviation of at least four experiments. The statistical significance between mean values was determined by a one-way analysis of variance, and the significance in differences of the mean values was evaluated by Tukey's post hoc test (SPSS v10.0; Chicago, IL, USA). $P \leq 0.05$ was considered significant.

\section{Results and discussion}

In this study, we evaluated the effect of gelatin incorporation into the $\mathrm{CPC}$ and enhancing phase conversion, physical properties, and osteoblastic cell responses of the cement using this natural polymer additive.

\section{Physical and mechanical properties}

Table 2 summarizes the results of some physical and mechanical properties of the studied CPCs. The initial setting time of the hydraulic CPC without any gelatin additive is $\sim 32 \mathrm{~min}$. It reduces to $\sim 18 \mathrm{~min}$ by adding $2 \mathrm{wt} . \%$ of gelatin to the cement liquid and further decrease is observed by adding 5 and 8 wt.\% of gelatin. Thus, the reduction in initial setting time depends on the concentration of gelatin, although no significant decrease $(P>0.05)$ is observed in concentrations higher than $5 \mathrm{wt} . \%$. The same results are also observed for the final setting time, and a decreasing trend is observed, depending on the gelatin content. The final setting time of CPC is $\sim 55 \mathrm{~min}$, which decreases to $32 \mathrm{~min}$ by using $8 \%$ of gelatin solution as liquid phase. The results demonstrate that the gelatin-containing CPCs are more appropriate for orthopedic applications. As the cements are intended to be used in the human body, the test was performed at $37^{\circ} \mathrm{C}$. Gelatin would not undergo sol-gel transition at $37^{\circ} \mathrm{C}$. Thus, the gelation process of the gelatin is negligible. In the authors' opinion, different mechanisms can be considered for the reduced initial setting time of gelatin-containing cements: 1) rapid hydration of the cement reactants because of the reduced $\mathrm{pH}$ of the gelatin solution in which the solution becomes supersaturated with respect to HA quickly; 2) gelatin favors fast precipitation and growth of HA nuclei; 3 ) the formation of calcium-gelatin complex through the interactions of $\mathrm{Ca}$ ions from the calcium salts and carboxylate ion from the gelatin. Moreover, the presence of gelatin provides a viscoelastic

Table 2 Setting times, compressive strength, and porosity of various CPCs

\begin{tabular}{|c|c|c|c|c|c|c|c|c|c|}
\hline Sample & $\begin{array}{l}\text { Is }(\mathrm{min}) \\
\text { at } 37^{\circ} \mathrm{C}\end{array}$ & $\begin{array}{l}\text { Fs }(\mathrm{min}) \\
\text { at } 37^{\circ} \mathrm{C}\end{array}$ & $\begin{array}{l}\text { CS after } \\
\text { incubation (Mpa) }\end{array}$ & $\begin{array}{l}\text { CS after } 7 \text { days } \\
\text { soaking (Mpa) }\end{array}$ & $P_{t}(\%)$ & $\mathbf{P}_{\mathrm{ma}}(\%)$ & $\mathbf{P}_{\mathrm{mi}}(\%)$ & $D_{b}\left(g / \mathrm{cm}^{3}\right)$ & $D_{p}\left(g / \mathrm{cm}^{3}\right)$ \\
\hline $\mathrm{CPC}$ & $32 \pm 5$ & $55 \pm 4$ & $1.13 \pm 0.25$ & $5.12 \pm 1.05$ & $29 \pm 3$ & 0 & $29 \pm 1$ & $2.13 \pm 0.01$ & 3.01 \\
\hline CPC-G2 & $18 \pm 3$ & $40 \pm 5$ & $3.27 \pm 0.17$ & $5.23 \pm 0.97$ & $3 I \pm 4$ & $4 \pm 2$ & $27 \pm 3$ & $2.00 \pm 0.02$ & 2.91 \\
\hline CPC-G5 & $1 \mathrm{I} \pm 4$ & $37 \pm 6$ & $2.90 \pm 0.76$ & $4.32 \pm 0.75$ & $37 \pm 3$ & $7 \pm 3$ & $30 \pm 4$ & $1.77 \pm 0.03$ & 2.81 \\
\hline CPC-G8 & $10 \pm 2$ & $32 \pm 3$ & $2.84 \pm 0.45$ & $4.19 \pm 1.01$ & $4 I \pm 4$ & $10 \pm 4$ & $3 I \pm 2$ & $1.59 \pm 0.03$ & 2.70 \\
\hline
\end{tabular}

Note: Data are presented as mean \pm standard deviation.

Abbreviations: CPC, calcium phosphate bone cement; CS, compressive strength; $D_{b}$, bulk density; $D_{p}$, powder density; Is, initial setting time; Fs, final setting time; $\mathrm{P}_{\mathrm{ma}}$, volume of the macropores; $\mathrm{P}_{\mathrm{mi}}$, volume of the micropores; $\mathrm{P}_{\mathrm{t}}$, total porosity. 
paste, which is able to prevent the light Gillmore needle penetration. For the final setting time, the accelerating effect of gelatin on apatite precipitation can be considered, which produces a hardened mass, and even resists against penetration of the heavyweight Gillmore needle.

Table 2 shows that gelatin induces $\sim 4 \%-10 \%$ macroporosity in the cement structure, depending on its concentration. Using $2 \%$ of gelatin solution as the cement liquid induces approximately $4 \%$ macroporosity into the cement structure, while the maximum pore content belongs to CPC-G8 $(10 \% \pm 4 \%)$. The macropore content of CPC-G5 is $7 \% \pm 3 \%$. These macropores can be considered as large defects in the cement structure, which will reduce the mechanical strength. Gelatin is lighter than calcium phosphate. Thus, the powder density reduces by incorporating gelatin in the cement composition, from 3.01 for CPC to $2.70 \mathrm{~g} \mathrm{~cm}^{-1}$ for CPC-G8. It is expected that the macroporosity favors apatite precipitation in gelatin-containing cement and improves biological functions of these cements compared to the conventional CPC (control group).

The CS of the control group is $\sim 1.13 \mathrm{MPa}$ after setting. The results show a substantial increase $(\sim 165 \%)$ in $\mathrm{CS}$ value of the cements using gelatin. An increase in CS of the cements has been observed after soaking in the SBF solution for 7 days; however, the same values are observed in all groups. Figure 1 shows the actual force/displacement curves obtained from the compressive mechanical tests of the samples before (Figure 1A) and after (Figure 1B) soaking in the SBF solution. In the as-set cements, all materials exhibit brittle behavior; however, a more elastic displacement is observed for the gelatin-containing ones. The slope of the stress/strain (followed by the force/displacement) curves in the linear region is representative of the elastic modulus (Ec). The figure indicates that the elastic modulus of the cements is influenced by the gelatin concentration, meanwhile the CPC without gelatin exhibits a higher Ec. After 7 days of soaking, the same force/displacement behavior is observed for all cements, and compared with the unsoaked samples, the elastic region decreases. In the force/displacement curves of gelatin-containing samples (in both Figure 1A and B), a nonlinear region is observed, which should not be confused with the plastic region. These fluctuations on the curves are due to the inhomogeneity of the contacting surfaces produced by the presence of the macropores during the structure destruction.

\section{Phase analysis and morphology}

Figure 2 shows XRD patterns of the as-set CPCs containing various amounts of gelatin. The diffraction pattern of the control group is also shown. The CPC as the control group

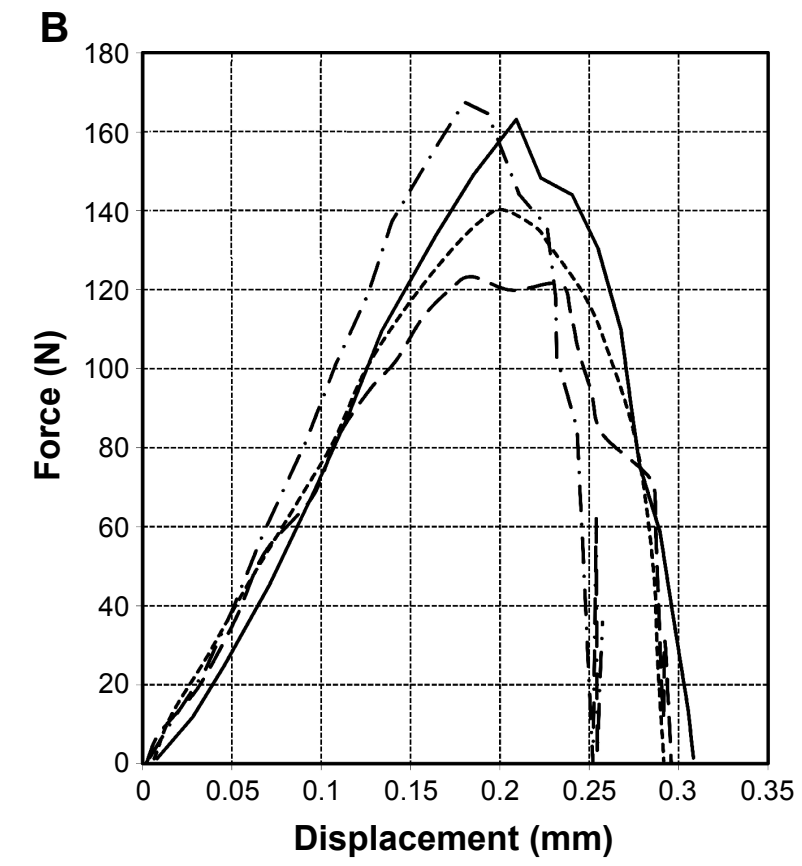

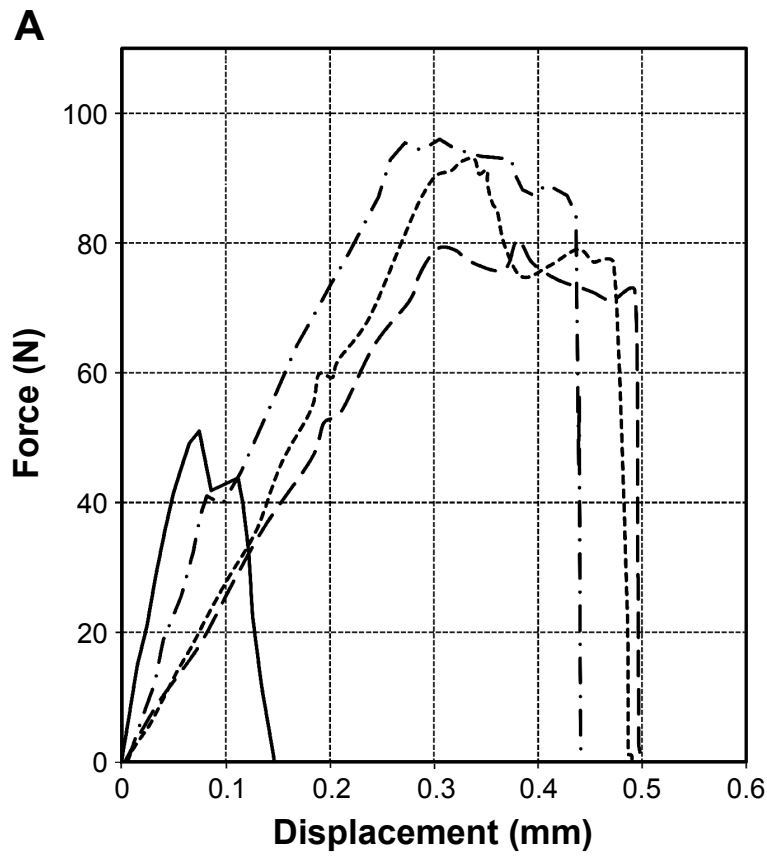

$$
\text { — CPC - CPC-G2 --.. CPC-G5 - - CPC-G8 }
$$

Figure I The actual force/displacement curves of various cements obtained from the compressive mechanical tests: the as-set cement (A) and the cements after soaking in the simulated body fluid solution (B).

Abbreviations: CPC, calcium phosphate bone cement; CPC-G2, calcium phosphate cement in which the liquid phase is a 2 wt\% gelatin solution; CPC-G5, calcium phosphate cement in which the liquid phase is a 5 wt\% gelatin solution; CPC-G8, calcium phosphate cement in which the liquid phase is a 8 wt\% gelatin solution. 


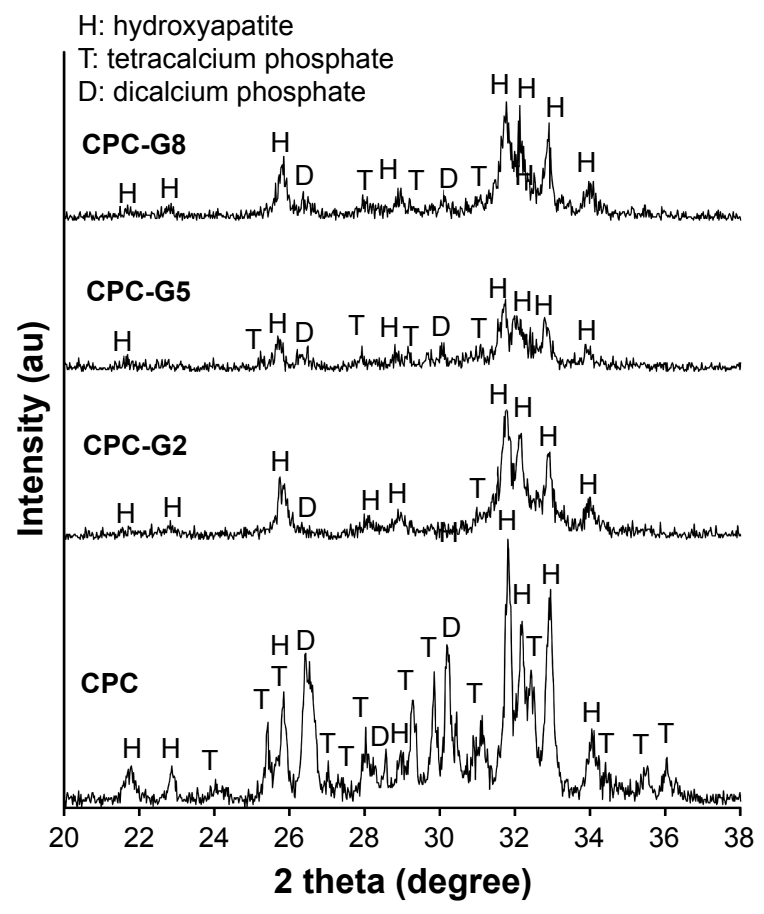

Figure $\mathbf{2}$ The X-ray diffraction analysis patterns of as-set CPCs containing various amounts of gelatin.

Abbreviations: CPC, calcium phosphate bone cement; CPC-G2, calcium phosphate cement in which the liquid phase is a $2 \mathrm{wt} \%$ gelatin solution; CPC-G5, calcium phosphate cement in which the liquid phase is a 5 wt\% gelatin solution; CPC$\mathrm{G} 8$, calcium phosphate cement in which the liquid phase is a $8 \mathrm{wt} \%$ gelatin solution.

is composed of the HA phase as well as some TTCP and DCPA. This means that there are still considerable amounts of the reactants in the cement composition. In contrast, for the gelatin-containing CPCs, apatite is the predominant phase, although small amounts of TTCP and DCPA are also found. The patterns confirm the promising effect of gelatin on HA precipitation. In other words, in this study, it was observed that HA precipitation was increased by introducing gelatin in the CPC composition. Gelatin can act as favorable sites of HA precipitation, meanwhile the carboxyl ions of gelatin can bond with $\mathrm{Ca}$ ions to form a complex, which favors the setting time as well.

In addition to the cohesion-promoting effect of gelatin, which increases the integrity of calcium phosphate particles, the gelatin molecules induced macroporosity in the cement structure. These special effects have influence on the cement integrity and biological and mechanical properties. In addition, two converse factors can play important roles in the final CS of the samples. The former is increase in the apatite phase and the latter is the amount and size of defects (such as pores) in the samples. Increase in HA formation leads to more entangled crystals, faster setting time, and, hence, higher CS, while the presence of macropores would result in decreased CS. According to the results, CS values of the as-set gelatin-doped CPCs are better than that of the control group. This can be related to the better HA precipitation and hence higher mechanical interlocking of the formed apatite crystals in these specimens, although the presence of macropores can negatively influence CS. The suggestion is confirmed by the results of XRD and SEM analyses. After soaking in the SBF solution, considerable content of the reactants is converted to HA in the control group, and thus, the CS of this specimen reaches the values of other groups.

Figure 3 shows the XRD patterns of the soaked cements. The patterns confirm that HA is the only phase observed after soaking the cements in the SBF for 7 days. The peak broadening shows that the formed apatite phase is poor crystalline. Moreover, the peak width increases (note the diffraction peaks at $2 \theta=25.7^{\circ}$ ) when higher amount of gelatin is incorporated.

Figure 4 shows the typical SEM images of CPCs containing different amounts of gelatin at low magnification. The figures show that macropores with a size range of $10-250 \mu \mathrm{m}$ are produced when gelatin is used. The macropores are produced because of the amphiphilic nature of gelatin, which entraps air bubbles and makes them stable. ${ }^{20,21}$ The size and distribution of the macropores differ by changing the concentration of gelatin molecules.

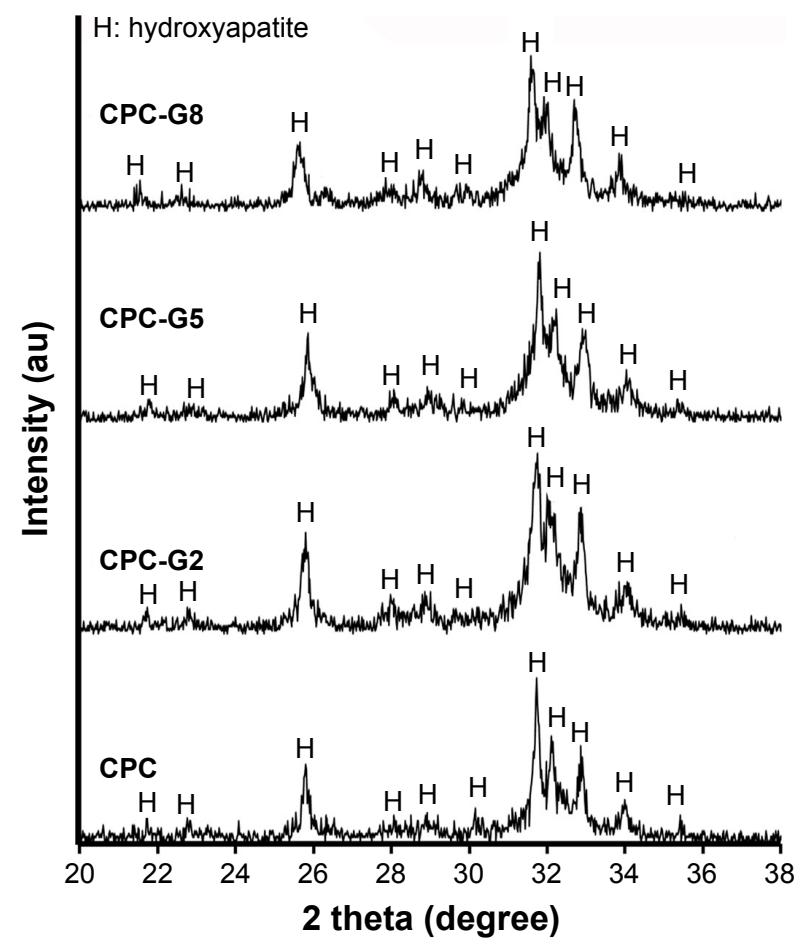

Figure 3 The X-ray diffraction analysis patterns of various CPCs after soaking in the simulated body fluid solution for 7 days.

Abbreviations: CPC, calcium phosphate bone cement; CPC-G2, calcium phosphate cement in which the liquid phase is a $2 \mathrm{wt} \%$ gelatin solution; CPC-G5, calcium phosphate cement in which the liquid phase is a $5 \mathrm{wt} \%$ gelatin solution; CPCG8, calcium phosphate cement in which the liquid phase is a $8 \mathrm{wt} \%$ gelatin solution. 



Figure 4 The low-magnification scanning electron microscopy images of CPCs containing different amounts of gelatin.

Abbreviations: CPC, calcium phosphate bone cement; CPC-G2, calcium phosphate cement in which the liquid phase is a 2 wt\% gelatin solution; CPC-G5, calcium phosphate cement in which the liquid phase is a 5 wt\% gelatin solution; CPC-G8, calcium phosphate cement in which the liquid phase is a 8 wt $\%$ gelatin solution.

Figure 5 shows the results of statistical evaluations using SemAphore software for large pores of various cements. This figure represents the pore size distribution of the cements in the range of $10-500 \mathrm{~nm}$. As observed, in CPC-G8, $75 \%$ of the large pores are in the range of $10-50 \mu \mathrm{m}$. In CPC-G2, a broader pore size distribution is observed and $30 \%$ of the large pores have a size of $200-250 \mu \mathrm{m}$. An intermediate situation is observed for CPC-G5.

The mercury intrusion porosimetry is a well-accepted method for the determination of pore size distribution of porous materials with interconnective pores. However, the SEM image shows that the pores produced by gelatin incorporation are not thoroughly interconnective. Thus, from the structural point of view, these cements should be improved to facilitate cell growth and resorption rate. Accordingly, statistical analysis of the SEM images using well-known softwares may be helpful. Nonetheless, it is challenging to use the SEM images for pore size determination. As the pores produced by the presence of gelatin are spherical, a value of average diameter derived from SEM images will underestimate the real average diameter of the pores. In fact, statistically, only a fraction of the randomly distributed spherical pores will be sectioned at the equator (max. diameter). On the contrary, most of the pores may not be crossed in line with the largest diameter. As a result, the measured average diameter will be smaller than the real one. Therefore, the SEM images can be used to compare the pore size in the different materials, but this is an approximate method, which gives a good estimation of the order of magnitude of the pore size but cannot give an accurate quantification of pore size distribution.

Figure 6 shows the microstructures of various cements (before and after soaking in SBF) at a high magnification $(\times 10 \mathrm{k})$. The SEM images confirm the results of XRD (Figures 2 and 3). For the as-set cements, the morphology of CPC is completely different from the gelatin-containing cements. In other words, in the as-set CPC (control group), polygonal particles of the reactants with nearly smooth surfaces and different particle sizes were observed, along with some micropores beside them. The particles are connected to each other. In contrast, all gelatin-containing cements were composed of entangled nanosized constituents with coarse and wrinkled morphology. According to the XRD data, these nanosized crystals are in apatite phase produced from the hydrolysis of TTCP and DCPA reactants in the presence of gelatin. When the cements are immersed in the SBF solution, the same morphologies are observed for them and no considerable difference between them can be pointed out. A dandelion-like nanomorphology is observed for all microstructures. It seems that the size and coarseness of the crystals increase after the soaking process. 


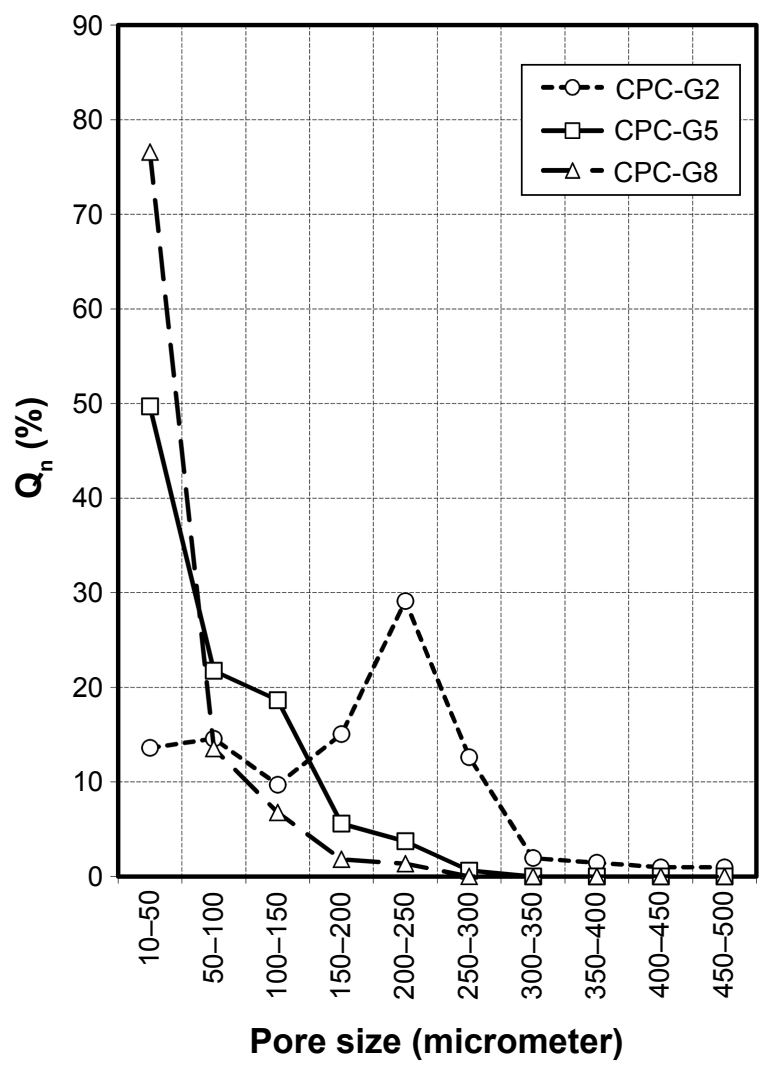

Figure 5 Size distribution of large pores $(10-500 \mu \mathrm{m})$ in the gelatin-containing cements calculated from the scanning electron microscopy images of cements using SemAphore software.

Abbreviations: CPC, calcium phosphate bone cement; CPC-G2, calcium phosphate cement in which the liquid phase is a $2 \mathrm{wt} \%$ gelatin solution; CPC-G5, calcium phosphate cement in which the liquid phase is a $5 \mathrm{wt} \%$ gelatin solution; CPC-G8, calcium phosphate cement in which the liquid phase is a 8 wt\% gelatin solution.

\section{FTIR spectra}

Figure 7 shows the FTIR spectra of the cements before (Figure 7A) and after (Figure 7B) soaking in the SBF solution. The FTIR spectra of gelatin powder and the mixture of TTCP and DCPA (cement powder) are also provided for comparison. In Figure 7A, the peak positions of the main chemical groups are marked on the patterns. The FTIR spectra of all gelatin-containing cements are nearly similar. In these samples, the bands at around 1,650 and 3,420 $\mathrm{cm}^{-1}$ are assigned to the hydroxyl group of adsorbed water, while the band that appeared at 3,600 is assigned to $\mathrm{OH}$ in apatite lattice. Moreover, the bands at 1,415 and 1,450 $\mathrm{cm}^{-1}$ are attributed to carbonate group in apatite lattice, which reflect the formation of carbonated apatite. The band at $950 \mathrm{~cm}^{-1}$ is also related to the $\mathrm{HPO}_{4}{ }^{2-}$ group. It confirms that the formed apatite is a calcium-deficient phase. The bands associated with amide II, $\mathrm{CH}$, and carbonyl groups are clearly observed in the spectra of gelatin, and are also found in the patterns of gelatin-containing cements. The bands at around
$1,700 \mathrm{~cm}^{-1}$ are also related to the carbonyl groups of gelatin, which may interact with $\mathrm{Ca}$ ions (to form, eg, calcium carboxylate complex). The complex may help to improve the setting time and mechanical strength of the cement, although its concentration is limited when the gelatin concentration is reduced. However, the FTIR spectrum of CPC is close to that of the cement powder, which confirms the results of XRD. As shown in Figure 7B, all calcium phosphate cements exhibit the same FTIR spectra after soaking in the SBF for 7 days. Compared to the as-set cement spectra, the absorption bands of $\mathrm{P}-\mathrm{O}$ at 570,607 , and $1,100 \mathrm{~cm}^{-1}$ are more intensive and less broad. This can be related to the growth of apatite phase and an increase in its crystallinity during the soaking period. The signs of carbonyl and $\mathrm{CH}$ bands of gelatin can be still found in the spectra of CPC-G5 and CPC-G8; however, the absorption band of the $\mathrm{CO}$ group at around $1,670 \mathrm{~cm}^{-1}$ has an overlap with that of $\mathrm{OH}$ (from adsorbed water).

\section{Gelatin release}

Thermal analysis and gelatin release test were performed to track what happens to gelatin when the cements are exposed to a physiological solution. The SBF solution was chosen for the gelatin release test, because its chemical simplicity was compared to the cell culture medium. In other words, the cell culture medium is more complex (due to the presence of various organic and inorganic compounds), which makes the gelatin detection difficult. TGA assists us to check the concentration of gelatin in the cement, because it is removed at a specific temperature during heating. Considering the liquid-to-powder ratio and concentration of gelatin in the cement liquid, the calculated quantities of gelatin polymer in the as-set cements are $1.26 \%$ for CPC-G2, 3.14\% for CPC-G5, and $4.95 \%$ for CPC-G8. Figure 8 shows the TGA curves of the as-set cements (Figure $8 \mathrm{~A}$ ) and cements soaked for 14 days (Figure 8B). The weight loss at $290^{\circ} \mathrm{C}-380^{\circ} \mathrm{C}$ relates to the removal of gelatin molecules (or complexes). ${ }^{22}$ The initial weight change $\left(90^{\circ} \mathrm{C}-150^{\circ} \mathrm{C}\right)$ is also assigned to the removal of adsorbed water. According to the TGA curves, the weight changes corresponding to the gelatin elimination are $1.33 \%, 3.30 \%$, and $4.98 \%$, for CPC-G2, CPC-G5, and CPC-G8, respectively. Thus, there is a good correlation between the TG data and the calculated data. Figure $8 \mathrm{~B}$ determines the presence of gelatin after soaking for 14 days. The picture inset reveals that the amounts of remaining gelatin in the soaked CPC-G2, CPC-G5, and CPC-G8 are 0.33\%, $0.40 \%$, and $0.38 \%$, respectively. Thus, it can be concluded that $\sim 60 \%$ of the initial gelatin has been released into the SBF solution during the soaking period. Figure 9 represents the 

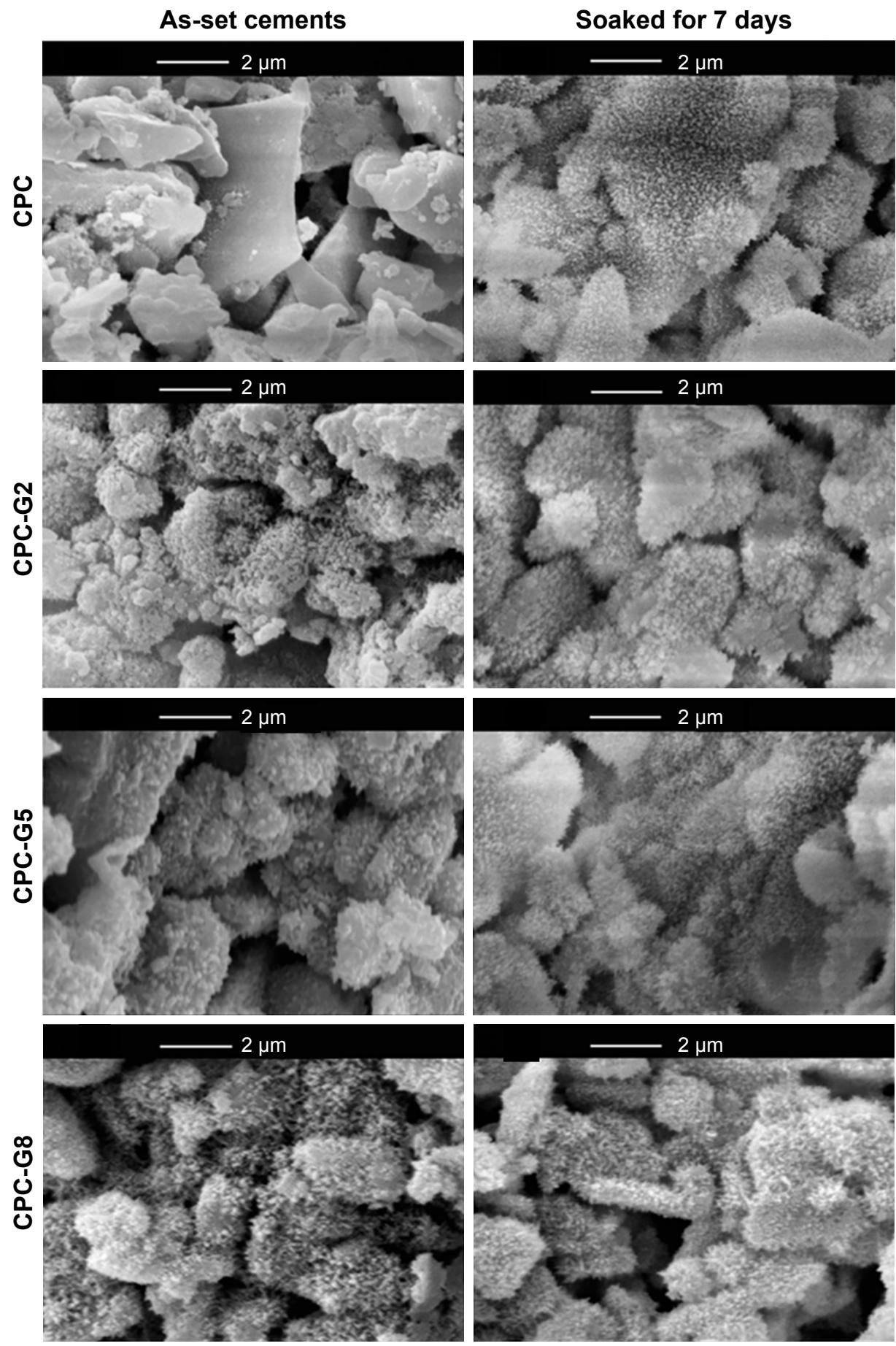

Figure 6 The high-magnification scanning electron microscopy images of various CPCs before and after soaking in simulated body fluid (magnification $\times 10$ k).

Abbreviations: CPC, calcium phosphate bone cement; CPC-G2, calcium phosphate cement in which the liquid phase is a 2 wt\% gelatin solution; CPC-G5, calcium phosphate cement in which the liquid phase is a 5 wt\% gelatin solution; CPC-G8, calcium phosphate cement in which the liquid phase is a 8 wt\% gelatin solution.

quantity of gelatin polymer released from the cements into the medium. The cumulative release percentages normalized with respect to the initial gelatin content are also provided (the values written above the points). It is reasonable that CPC-G8 delivers higher amounts of gelatin, because it contains higher gelatin in its initial composition. However, the percentage of the released gelatin is nearly equal for all cements. This figure shows that the cements are able to leak the incorporated gelatin, although the released quantity is restricted. On the basis of the release test, $65 \%-68 \%$ of the incorporated gelatin is released, and regarding the standard deviations, these data are in agreement with those of TGA. 

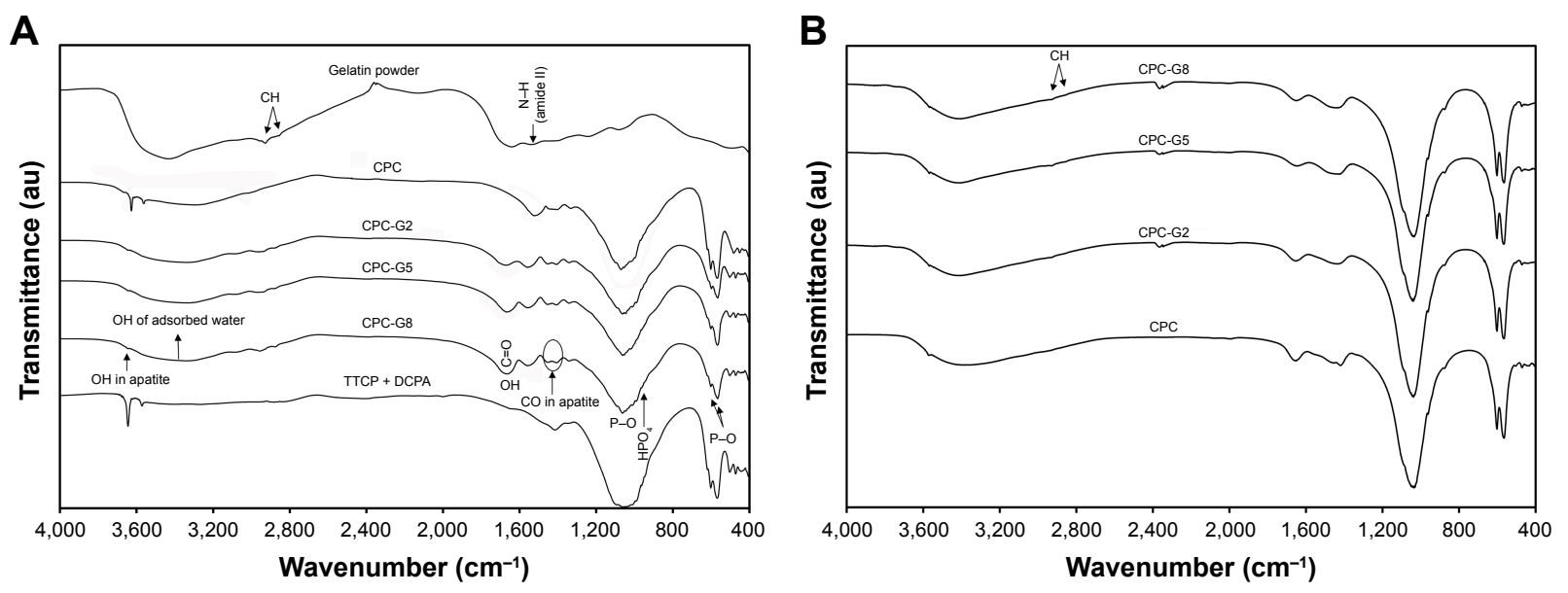

Figure 7 The Fourier transforming infrared spectra of cements: as-set cements in comparison with gelatin powder and TTCP + DCPA cement powder (A) and the cements after soaking for 7 days (B).

Abbreviations: CPC, calcium phosphate bone cement; DCPA, dicalcium phosphate anhydrate; TTCP, tetracalcium phosphate; CPC-G2, calcium phosphate cement in which the liquid phase is a 2 wt\% gelatin solution; CPC-G5, calcium phosphate cement in which the liquid phase is a 5 wt\% gelatin solution; CPC-G8, calcium phosphate cement in which the liquid phase is a 8 wt\% gelatin solution.

The limited release of gelatin can be related to the interaction of these molecules with $\mathrm{Ca}$ ions of the cement and the confinement of them among/under the grown/growing apatite crystals.

\section{Cell behaviors}

In the MTT assay, some enzymatic reactions reduce MTT reagent to a formazan product. Therefore, the absorbance of formazan imitates the level of cell metabolism. This procedure is known as cell viability in culture medium. Figure 10 shows the number of viable cells on the cement surfaces containing different amounts of gelatin. The cement

A

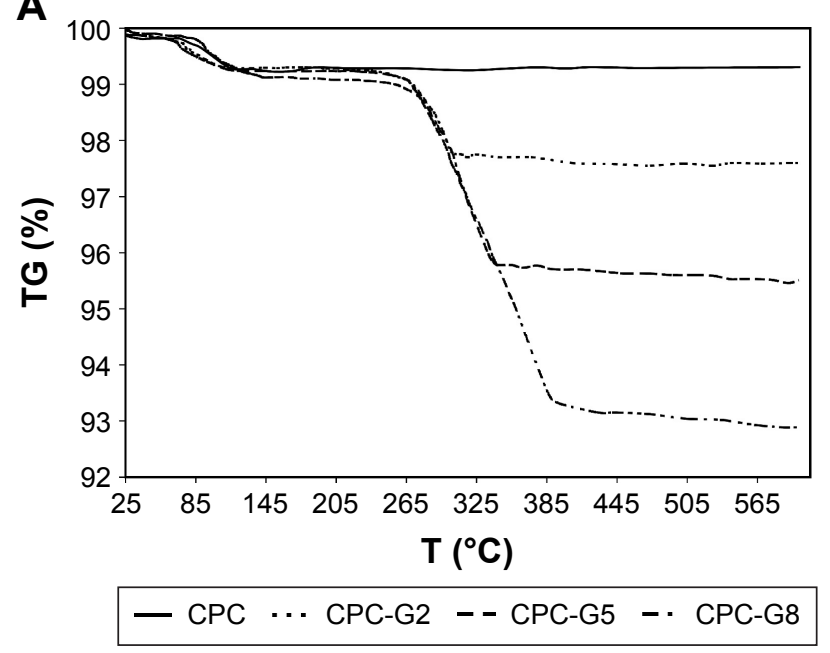

specimens (with and without gelatin) were seeded with 10,000 cells per sample. After $24 \mathrm{~h}$, in gelatin-containing groups, more cells are found, that is, the seeding efficiency is higher and the addition of gelatin seems to have some effect on cell adhesion. However, according to MTT results, all experimental groups do not have exactly 10,000 cells per sample after $24 \mathrm{~h}$. This can be related to the normal rate of dead cells in suspension and the normal rate of nonadherent cells. For all samples, a sustained increase in cell numbers (proliferation) is observed with increasing culture time. After 3 days, it is observed that the gelatin addition increased osteoblast cells proliferation, because there is significant

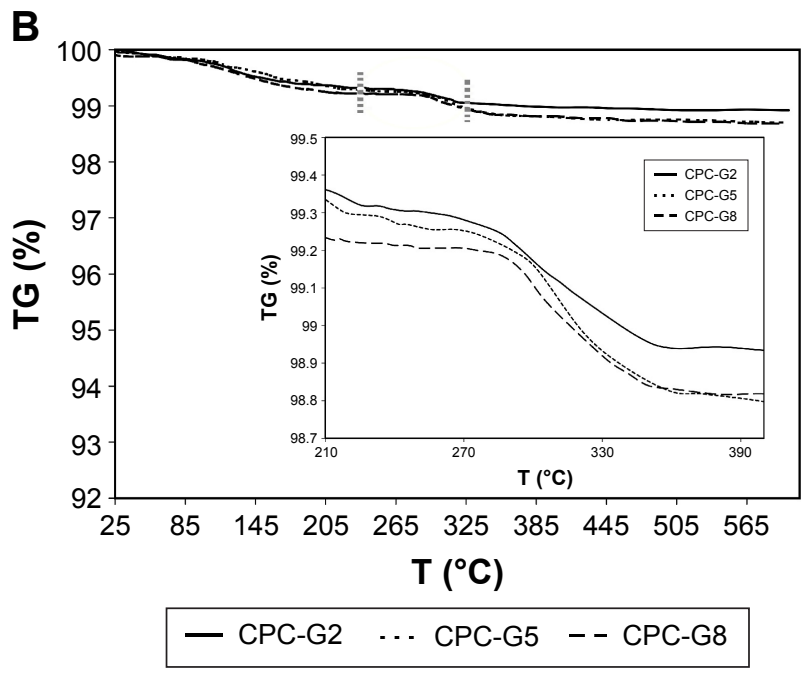

Figure 8 The thermogravimetry analysis curves of the as-set cements (A) and the cements soaked for I4 days (B).

Abbreviations: CPC, calcium phosphate bone cement; TG, thermogravimetry analysis; CPC-G2, calcium phosphate cement in which the liquid phase is a 2 wt\% gelatin solution; CPC-G5, calcium phosphate cement in which the liquid phase is a 5 wt $\%$ gelatin solution; CPC-G8, calcium phosphate cement in which the liquid phase is a 8 wt\% gelatin solution. 


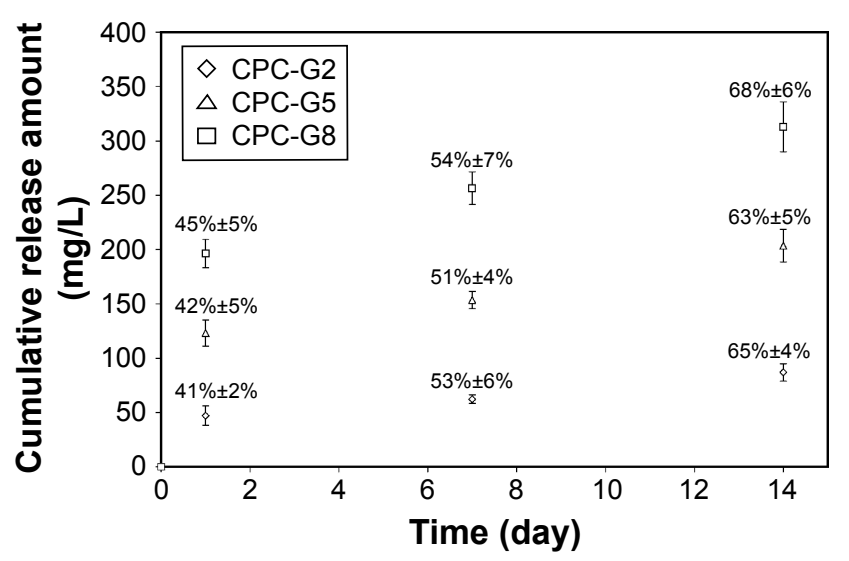

Figure 9 The cumulative quantity of the released gelatin along with the release percentage of each cement composition (the values written above the points). Abbreviations: CPC, calcium phosphate bone cement; CPC-G2, calcium phosphate cement in which the liquid phase is a 2 wt\% gelatin solution; CPC-G5, calcium phosphate cement in which the liquid phase is a $5 \mathrm{wt} \%$ gelatin solution; CPCG8, calcium phosphate cement in which the liquid phase is a $8 \mathrm{wt} \%$ gelatin solution.

difference $(P<0.05)$ between the cell numbers of CPC group and samples with gelatin. The cell numbers increase by culture time from day 3 to day 7 and the differences in the cell numbers between the control group and cements CPC-G5 and CPC-G8 are statistically significant, at each of the time intervals mentioned.

According to the results of gelatin release experiment, it is found that before day $7, \sim 50 \%$ of the incorporated gelatin is present in the cement (and even cement surface) that amplifies cell attachment and the proliferation. Regarding the XRD data, after the setting and at days 1 and 3 , most of the phase that existed in gelatin-containing samples is nanohydroxyapatite with a rough and needle-like morphology (see SEM images). The surface roughness of the samples is also an important

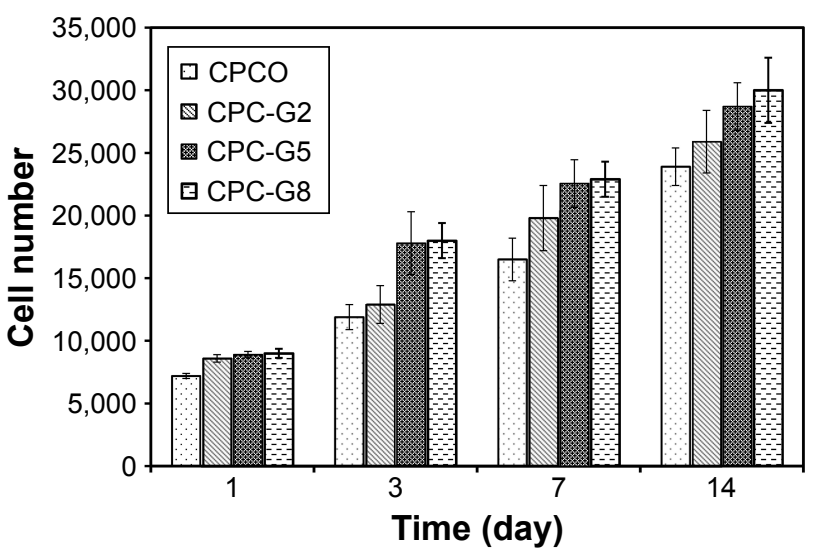

Figure 10 The numbers of viable cells on the cement surfaces containing different amounts of gelatin.

Abbreviations: CPC, calcium phosphate bone cement; CPC-G2, calcium phosphate cement in which the liquid phase is a 2 wt\% gelatin solution; CPC-G5, calcium phosphate cement in which the liquid phase is a 5 wt\% gelatin solution; CPCG8, calcium phosphate cement in which the liquid phase is a 8 wt \% gelatin solution.

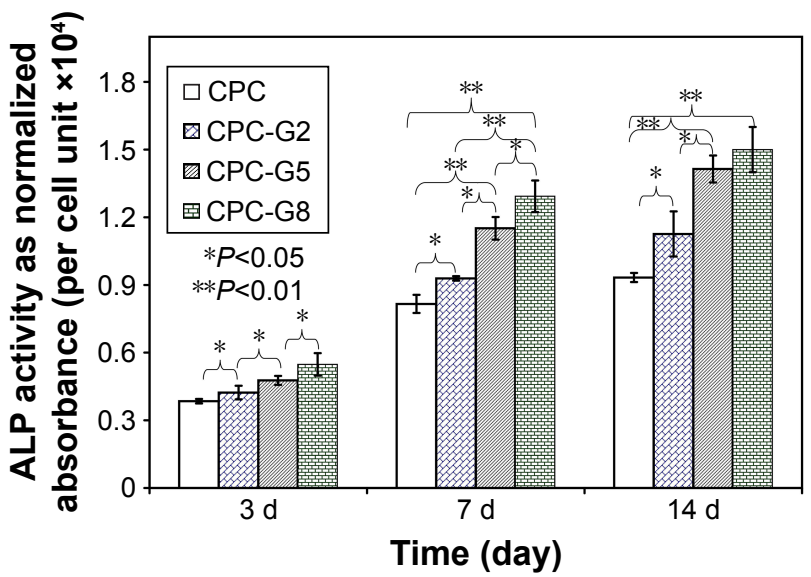

Figure II The amount of alkaline phosphatase (ALP) enzyme produced in the osteoblasts over a period of time $(* P<0.05$, $* * P<0.01)$.

Abbreviations: CPC, calcium phosphate bone cement; CPC-G2, calcium phosphate cement in which the liquid phase is a 2 wt\% gelatin solution; CPC-G5, calcium phosphate cement in which the liquid phase is a $5 \mathrm{wt} \%$ gelatin solution; CPCG8, calcium phosphate cement in which the liquid phase is a $8 \mathrm{wt} \%$ gelatin solution.

reason for better cell attachment and proliferation of them. ${ }^{23}$ At days 7 and 14, 55\% and $65 \%$ of the loaded gelatin was lost in the medium (see release experiment), and it is suggested that the surface had very little gelatin content (gelatin is removed from the surface more efficiently). The XRD and SEM data suggest that, after 7 days, the phase composition and morphology of all cement surfaces are similar. However, the higher cell numbers in CPC-G5 and CPC-G8 can be assigned to the higher cell attachment of these samples at days 1 and 3. The stimulating effect of gelatin on the osteoblasts has been also noticed in previous works. Teotia et al synthesized injectable bone cement incorporated with gelatin as a bioactive molecule to improve cellular interaction. ${ }^{10}$ Suarasan et al showed that coating gelatin on gold nanoparticles enhanced cell proliferation and osteoblasts differentiation with bone nodule formation. ${ }^{24}$

Figure 11 represents the amount of ALP enzyme produced in the osteoblasts over a period of time. The amount of ALP that was normalized based on the numbers of the proliferated cells, improved with the progress of culture time, but as shown in Figure 11, higher ALP activity was observed on gelatin-containing CPCs compared with that of the control group. For all periods, the differences between the ALP activity of the cells on CPC, CPC-G5, and CPC-G8 are statistically significant. Our results are in line with the previous studies, which reported better ALP activity of osteoblastic cells in the presence of gelatin..$^{25,26}$

Figure 12 shows different magnifications of the SEM image, which indicate osteoblast spreading on the 7-daycultured cements (four top micrographs were taken at 

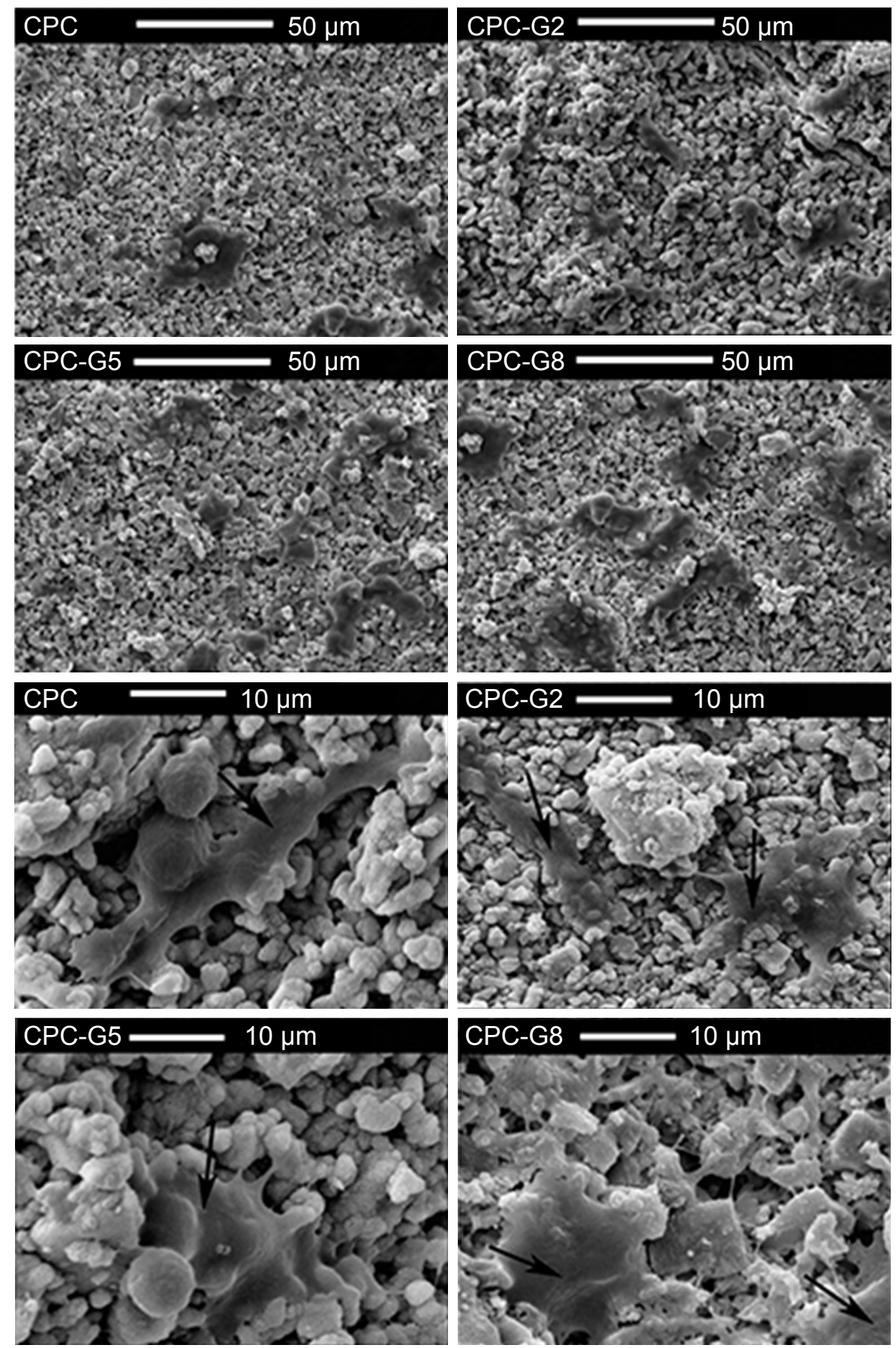

Figure 12 Morphology of the G-292 osteoblastic cells attached on the surfaces of 7-day-cultured cements (magnification of the four top pictures is $\times 750$ and of the four bottom pictures is $\times 3,000$ ).

Abbreviation: CPC, calcium phosphate bone cement; CPC-G2, calcium phosphate cement in which the liquid phase is a 2 wt\% gelatin solution; CPC-G5, calcium phosphate cement in which the liquid phase is a 5 wt\% gelatin solution; CPC-G8, calcium phosphate cement in which the liquid phase is a 8 wt\% gelatin solution.

magnification $\times 750$, four bottom images were taken at magnification $\times 3,000$ ). As observed in the low-magnification images, there is a relatively long distance between the cells and they have attached onto the cement surfaces separately. This is related to the low cell seeding density $\left(10,000\right.$ cell/79 $\left.\mathrm{mm}^{2}\right)$. Cells with well-extended membrane are observed here. The higher magnification shows the interaction of the cells with the surface underneath. The background of all cements is porous and composed of rough balls. For all samples, sheet-like cells with well-spread cytoplasmic membrane are observed. For the cements with 5 and especially 8 wt. $\%$ gelatin, fibrils at the cell edges are observed, which can reflect more cell-cell and cell-surface interactions. The fibrils can be filopodia. The releasing 
ability of gelatin from the cement into the SBF solution was confirmed in this study. The gelatin molecules can also be released into the cell culture medium similarly. The gelatin molecules may produce Arg-Gly-Asp (RGD) motifs. The RGD motifs can mediate cell attachment through interaction with integrin, a transmembrane receptor, which is a bridge for cell-cell and cell-extracellular matrix interactions. ${ }^{10}$ These interactions would result in better cell responses and biocompatibility. The gelatin molecules can also produce improved cell responses indirectly through promoting effect on apatite precipitation. It has been proved that the needlelike apatite crystals enhance cell behaviors and produce better cell responses. ${ }^{23}$ However, it should be noted that the G-292 cells used in this study are osteosarcoma cells and they may not totally represent normal osteoblastic cells. Thus, further studies using other osteoblastic cells are under consideration. As the main restriction of CPCs is their relatively slow degradation rate, development of porous self-setting cement is a suitable strategy to decrease these limitations. The presence of macropores would assist the bone tissue progress and the cement resorption. In this work, a gelatin-based calcium phosphate cement foam with improved apatite formation ability and physical and mechanical properties was developed. The improved cell behaviors of gelatin-doped CPCs may suggest successful in vivo performance of these cements. It is anticipated that the cellular degradation of the porous cements will considerably increase followed by the bone formation. It is obvious that more in vivo tests are needed to authenticate these claims.

\section{Conclusion}

From the results of this study, the following conclusions can be pointed out:

- Using gelatin molecules in the composition of calcium phosphate cements accelerates the hydraulic reactions, resulting in fast apatite precipitation. The coarseness and the size of the apatite crystals are influenced by the gelatin as well. The formation of apatite crystals is indicative of the cement bioactivity and its bone-bonding ability.

- The gelatin molecules in the cement composition reduce the cement setting time and improve the CS. The cements are brittle, but the extent of brittleness is slightly reduced by the presence of gelatin.

- The presence of gelatin molecules induces some macropores into the cement structure, but the size and distribution of the pores depend on the gelatin concentration.
- Some of the gelatin molecules can be released from the cement into the physiological solution, which is probably responsible for the improved cell behaviors of the cements.

- The CPCs with gelatin additive reveal better osteoblastic cell proliferation and ALP activity.

\section{Acknowledgment}

The authors wish to acknowledge Materials and Energy Research Center for financial support of this work by the grant number 781393052 .

\section{Disclosure}

The authors report no conflicts of interest in this work.

\section{References}

1. Zhang J, Liu W, Schnitzler V, Tancret F, Bouler JM. Calcium phosphate cements for bone substitution: chemistry, handling and mechanical properties. Acta Biomater. 2014;10(3):1035-1049.

2. Kobayashi N, Ong K, Villarraga M, et al. Histological and mechanical evaluation of self-setting calcium phosphate cements in a sheep vertebral bone void model. J Biomed Mater Res A. 2007;81(4): $838-846$.

3. Hesaraki S, Moztarzadeh F, Sharifi D. Formation of interconnected macropores in apatitic calcium phosphate bone cement with the use of an effervescent additive. J Biomed Mater Res A. 2007;83(1):80-87.

4. Aryaei A, Liu J, Jayatissa AH, Champa Jayasuriya A. Crosslinked chitosan improves the mechanical properties of calcium phosphate-chitosan cement. Mater Sci Eng C Mater Biol Appl. 2015;54: $14-19$.

5. Wang P, Song Y, Weir MD, et al. A self-setting iPSMSC-alginatecalcium phosphate paste for bone tissue engineering. Dent Mater. 2016; 32(2):252-263.

6. Liu W, Zhang J, Rethore G, et al. A novel injectable, cohesive and toughened Si-HPMC (silanized-hydroxypropyl methylcellulose) composite calcium phosphate cement for bone substitution. Acta Biomater. 2014;10:3335-3345.

7. Zhou ZQ, Ye DP, Liang WG, Wang B, Zhu ZZ. Preparation and characterization of a novel injectable strontium-containing calcium phosphate cement with collagen. Chin J Traumatol. 2015;18(1):33-38.

8. Gil-Albarova J, Vila M, Badiola-Vargas J, Sánchez-Salcedo S, Herrera A, Vallet-Regi M. In vivo osteointegration of three-dimensional crosslinked gelatin-coated hydroxyapatite foams. Acta Biomater. 2012; 8(10):3777-3783.

9. Li M, Liu X, Liu X, Ge B. Calcium phosphate cement with BMP-2loaded gelatin microspheres enhances bone healing in osteoporosis: a pilot study. Clin Orthop Relat Res. 2010;468(7):1978-1985.

10. Teotia AK, Gupta A, Raina DB, Lidgren L, Kumar A. Gelatin-modified bone substitute with bioactive molecules enhance cellular interactions and bone regeneration. ACS Appl Mater Interfaces. 2016;8(17): 10775-10787.

11. Habraken WJ, de Jonge LT, Wolke JG, Yubao L, Mikos AG, Jansen JA. Introduction of gelatin microspheres into an injectable calcium phosphate cement. J Biomed Mater Res A. 2008;87(3):643-655.

12. Montufar EB, Traykova T, Schacht E, et al. Self-hardening calcium deficient hydroxyapatite/gelatine foams for bone regeneration. J Mater Sci Mater Med. 2010;21(3):863-869.

13. Hesaraki S, Moztarzadeh F, Solati-Hashjin M. Phase evaluation of an effervescent-added apatitic calcium phosphate bone cement. J Biomed Mater Res B Appl Biomater. 2006;79(2):203-209. 
14. Hesaraki S. Feasibility of alumina and alumina-silica nanoparticles to fabricate strengthened betatricalcium phosphate scaffold with improved biological responses. Ceram Int. 2016;42(6):7593-7604.

15. Leonor IB, Balas F, Kawashita M, Reis RL, Kokubo T, Nakamura T. Biomimetic apatite deposition on polymeric microspheres treated with a calcium silicate solution. J Biomed Mater Res B Appl Biomater. 2009; 91(1):239-247.

16. Pankongadisak P, Ruktanonchai UR, Supaphol P, Suwantong O. Preparation and characterization of silver nanoparticles-loaded calcium alginate beads embedded in gelatin scaffolds. AAPS Pharm Sci Tech. 2014;15(5):1105-1115.

17. Jaiswal M, Gupta A, Dinda AK, Koul V. An investigation study of gelatin release from semi-interpenetrating polymeric network hydrogel patch for excision wound healing on Wistar rat model. J Appl Polymer Sci. 2015;132(5):2-10.

18. Amjadian S, Seyedjafari E, Zeynali B, Shabani I. The synergistic effect of nano-hydroxyapatite and dexamethasone in the fibrous delivery system of gelatin and poly(1-lactide) on the osteogenesis of mesenchymal stem cells. Int J Pharm. 2016;507(1-2):1-11.

19. Tsai WB, Chen RP, Wei KL, et al. Polyelectrolyte multilayer films functionalized with peptides for promoting osteoblast functions. Acta Biomater. 2009;5(9):3467-3477.

20. Lin L, Chen C. Preparation and surface activity of gelatin derivative surfactants. Colloids Surf A Physicochem Eng Asp. 2006;272(1):8-14.
21. Djagny VB, Wang Z, Xu S. Gelatin: a valuable protein for food and pharmaceutical industries: review. Crit Rev Food Sci Nutr. 2001;41(6): 481-492.

22. Jakir Hossan MD, Gafur MA, Kadir MR, Karim MM. Preparation and characterization of gelatin hydroxyapatite composite for bone tissue engineering. Int J Eng Tech. 2014;14:24-32.

23. Hesaraki S, Nazarian H, Pourbaghi-Masouleh M, Borhan S. Comparative study of mesenchymal stem cells osteogenic differentiation on lowtemperature biomineralized nanocrystalline carbonated hydroxyapatite and sintered hydroxyapatite. J Biomed Mater Res B Appl Biomater.2014; 102(1):108-118.

24. Suarasan S, Focsan M, Soritau O, Maniu D, Astilean S. One-pot, green synthesis of gold nanoparticles by gelatin and investigation of their biological effects on Osteoblast cells. Colloids Surf B Biointerfaces. 2015;132:122-131.

25. Kang H, Shih YR, Hwang Y, et al. Mineralized gelatin methacrylatebased matrices induce osteogenic differentiation of human induced pluripotent stem cells. Acta Biomater. 2014;10(12):4961-4970.

26. Perez RA, Del Valle S, Altankov G, Ginebra MP. Porous hydroxyapatite and gelatin/hydroxyapatite microspheres obtained by calcium phosphate cement emulsion. J Biomed Mater Res B Appl Biomater. 2011;97(1): $156-166$.
International Journal of Nanomedicine

\section{Publish your work in this journal}

The International Journal of Nanomedicine is an international, peerreviewed journal focusing on the application of nanotechnology in diagnostics, therapeutics, and drug delivery systems throughout the biomedical field. This journal is indexed on PubMed Central, MedLine, CAS, SciSearch $\AA$, Current Contents ${ }^{\circledR} /$ Clinical Medicine,

\section{Dovepress}

Journal Citation Reports/Science Edition, EMBase, Scopus and the Elsevier Bibliographic databases. The manuscript management system is completely online and includes a very quick and fair peer-review system, which is all easy to use. Visit http://www.dovepress.com/ testimonials.php to read real quotes from published authors. 